\title{
Understanding Climate Changes in Malaysia Through Space Weather Study
}

\author{
Z. S. Hamidi ${ }^{1,4, *}$, N. N. M. Shariff ${ }^{2}$, C. Monstein ${ }^{3}$ \\ ${ }^{1}$ MARA University of Technology, 40450, Shah Alam, Selangor, Malaysia \\ ${ }^{2}$ Department of Science and Technology Studies, University of Malaya, 50603, \\ Kuala Lumpur, Malaysia \\ ${ }^{3}$ Institute of Astrophysics, ETH, Zurich, Switzerland \\ ${ }^{4}$ Department of Physics, University of Malaya, 50603, Kuala Lumpur, Malaysia \\ *E-mail address: zetysh@salam.uitm.edu.my
}

\begin{abstract}
Space weather has a close connection with the interaction of the Earth and the Sun. As equatorial country, the characteristic features of the climate of Malaysia are uniform temperature, very high humidity and copious rainfall. Malaysia has an average of temperature of $26.7^{\circ} \mathrm{C}$ per year. Therefore, it is suitable to monitor the Sun. In the following work, we will emphasize the development of Sun monitoring in Malaysia. The number of observatories are increasing. A dedicated work to understand the Sun activity in radio region is a part of an initiative of the United Nations together with NASA in order to support developing countries participating in 'Western Science' research. Realizing how important for us to monitor the space weather, therefore, we have been utilizing the new radio spectrometer, CALLISTO (Compound Low Cost Low Frequency Transportable Observatories) spectrometer. Malaysia is one of the earliest country from South- East Asia (ASEAN) that involve this research. One of the advantages to start the solar monitoring in Malaysia is because our strategic location as equator country that makes possible to observing a Sun for 12 hours daily throughout a year. We strongly believe that Malaysia as one of contributor of solar activity data through ECALLISTO network. This is a very good start for developing a space weather in Malaysia. With the implementation of CALLISTO systems and development of solar monitoring network, a new wavelength regime is becoming available for solar radio astronomy. Overall, this article presents an overview of space weather in Malaysia. With the present level of the international collaboration, it is believed that the potential involvement of local and international scientist in space weather will increase.
\end{abstract}

Keywords: Space Weather; Sun; Compound Astronomical Low-cost Low-frequency Instrument for Spectroscopy in Transportable Observatories (CALLISTO); solar activity

\section{INTRODUCTION}

Space weather is one of the important issue in global society. It has a connection with a climate changes that could affected the Earth. This study also has a close connection with the 
solar activity. The solar activity can be characterized with a patter so-called solar cycle. Cuurently, we are in the cycle of $24^{\text {th }}$ which was start since 4th January 2008. It is believed that the 24th solar cycle will be less energetic than the last maximum in $2002-2003$. Overall energetic eruptions seem to be less frequent in cycle 24 as shown by the lower number of type II radio bursts, full halo CMEs, and interplanetary shocks. The profile of cycle 24 was determined by the maximum phase of cycle 23 and the deep minimum of the preliminary phase of cycle 24. Decade observations have also revealed that solar protons could sometimes be accelerated up to tens of $\mathrm{GeV}$ in some intense solar energetic process. The latest observations are extremely deficient in the radio and X-ray synoptic and diagnostic influence on these coronal phenomena rich of physics they could reveal.

A number of dedicated studies of the solar radio burst have made great progress in more than a decade beginning with ground observation and become one of the most significant current discussions on space weather issue. The solar flare and CMEs (Coronal Mass Ejections) that can affect life on the surface of the Earth, particularly the increasingly technologically sophisticated devices that are part of modern life [1]. Solar radio observation has been carried out since 1944 when J.S Hey discovered that the Sun emits radio waves [2]. This radio region covers from $15 \mathrm{MHz}$ to $30 \mathrm{GHz}$ while optical region from $1.3343 \times 10^{-15} \mathrm{~Hz}$ $-2.3349 \times 10^{-15} \mathrm{~Hz}$.

The Coronal Mass Ejections (CMEs), a multi-thermal radiation has been studied extensively since 1970s. The CME phenomenon was discovered only in 1971 [3] but has become the most important form of solar activity because it is the most energetic phenomena on the Sun with a wide range influence throughout the heliosphere. The front speeds could exceed up to $3000 \mathrm{~km} / \mathrm{s}$ [4-6]. As the largest scale eruptive phenomenon in the solar atmosphere, it can be observed as observed as enhanced brightness propagating out from coronal-loop-sized scale $\left(10^{4} \mathrm{~km}\right)$, expand to cover a significant part of the solar surface which is responsible for the most extreme space weather effects on Earth. This phenomenon can exhibit a variety of forms, some having the classical "three-part" structure [7].

Previous study shown that CMEs associated with solar flares have a higher median speed than those associated with eruptive filaments and that the median speed of CMEs associated with strong flares is higher than that of weak-flare - associated CMEs. Solar flare is considered as a high energetic and complicated phenomenon in which mass eruptions occur, energetic particles are generated and highly energy radiations are emitted. During a flares, large quantities of energy are transferred between the corona and chromosphere through thermal conduction, non-thermal particle beams, radiation transport and mass motions. This event is triggered by fast drift of individual sunspot proper motion within the complex magnetic configuration due to instabilities of equilibrium of coronal magnetic field.

\section{SOLAR OBSERVATION}

In this work, our discussion of the development solar radio astronomy in Malaysia will be highlighted. This is not only from scientific aspects, it is also covered from antenna design to communication and radar technologies [8-11]. Malaysia becomes the 19th countries that involve this research. We started by proposing this research in early 2011, through the National Space Agency of Malaysia (ANGKASA), University of Malaya (UM), National University of Malaysia (UKM) and the MARA University of Technology (UiTM) [12].

Previous studies investigated the indication of radio frequency interference (RFI) [1315]. In the future, we plan to implement the method of the Very Long Baseline Interferometer 
(VLBI) observations in Malaysia may encounter [16,17]. By 2011, we have constructed 6 meters Log Periodic Dipole Antenna (LPDA) and successfully set-up the CALLISTO system at National Space Centre, Banting Selangor on 20th February 2012 [11,18]. Start from that, a daily data beginning from $7.30 \mathrm{am}$ to $19.30 \mathrm{pm}$ is automatically stored [19]. This data also accessible on CALLISTO website: http://www.e-callisto.org/ and can be compared with other sites. The current distribution of CALLISTO system is illustrated in Figure 1.

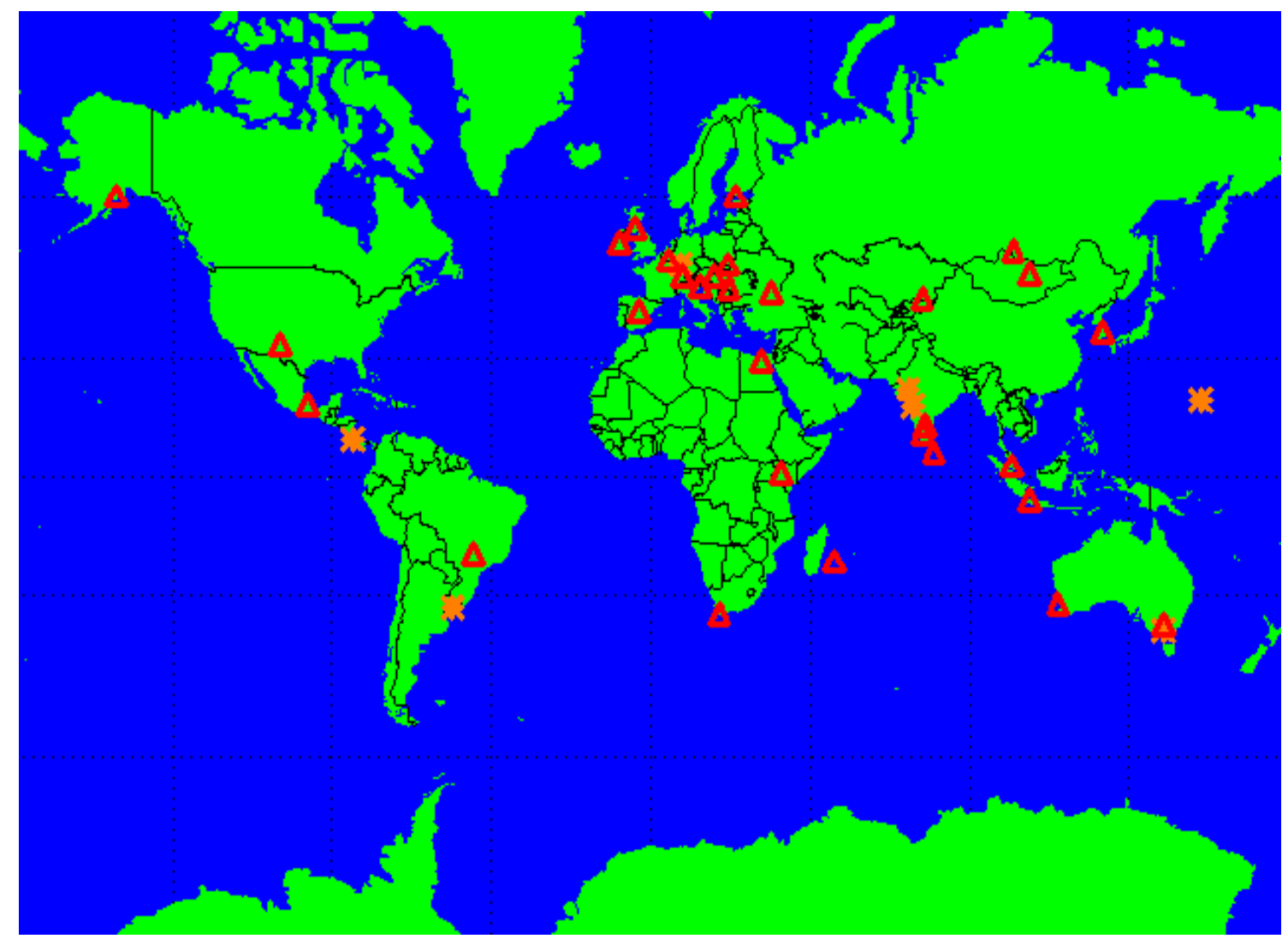

Figure 1. Map of current distribution of Callisto instruments in March 2014.

The main objective is to monitor the solar activities (solar flares and CMEs) within 24 hours all over the world has positively turned to reality [20]. A combination of instrument deployment, analysis and interpretation of space weather data from the deployed instruments in conjunction with space data, and communicate the results to the public play an important role to make the aim become possible. One of the strategies is to develop the scientific insight necessary to understand the science, and to reconstruct and forecast near-Earth space weather. This includes instrumentation, data analysis, modeling, education, training, and public outreach. The Compound Astronomical Low-cost Low-frequency Instrument for Spectroscopy in Transportable Observatories (CALLISTO) spectrometer is a heterodyne receiver designing and leading by Christian Monstein and Radio and Plasma Physics Group from ETH Zurich, Switzerland [21]. There are a few designs of a frequency-agile or sweptfrequency spectrometers, which are currently in operation in several places, including China, Hiraiso, Ondrejov, Sao Paolo and Tremsdorf . Up to 2014, there are 36 stations around the world that actively observe the Sun routinely. Up to date, this project has successfully achieved more than $90 \%$ target in order to monitor the Sun within 24 hours. Due to 12 hours 
monitoring, Malaysia almost covered fifty per cent of the CALLISTO data. This make our data more consistent.

Observational data are limited only a good range of frequency with minimum interference. In order to keep data only with high probability of containing solar radio flares, a filter method also be used from time to time. This data can also be compared with the National Oceanic and Atmospheric Administration (NOAA) list is in an updated state. Data archive allows to store up to 10 TBytes of FIT-files. The archive is physically located at FHNW (Fachhochschule Nordwestschweiz) and managed from ETH in Zurich).

The construction of the antenna has started since December 2011 and successfully installed at the National Space Center, Banting Selangor on $20^{\text {th }}$ February 2012 [19]. We also do some testing and in the antenna is supported by $3 \times 3$ meter tripod. The system of CALLISTO is setup at the top of the building. In order to learn in detailed regarding the operation of the CALLISTO system, we are attending the CALLISTO workshop organized by the ANGKASA (National Space Agency) that has been held from $22^{\text {nd }}$ February $-26^{\text {th }}$ February 2012. This workshop is conducted by Christian Monstein, from Institute of Astrophysics, Switzerland. The location of the National Space Centre Banting is at Selangor, Malaysia as in Figure 2. The location of the system is strategic seems the three universities are also located at the same state.

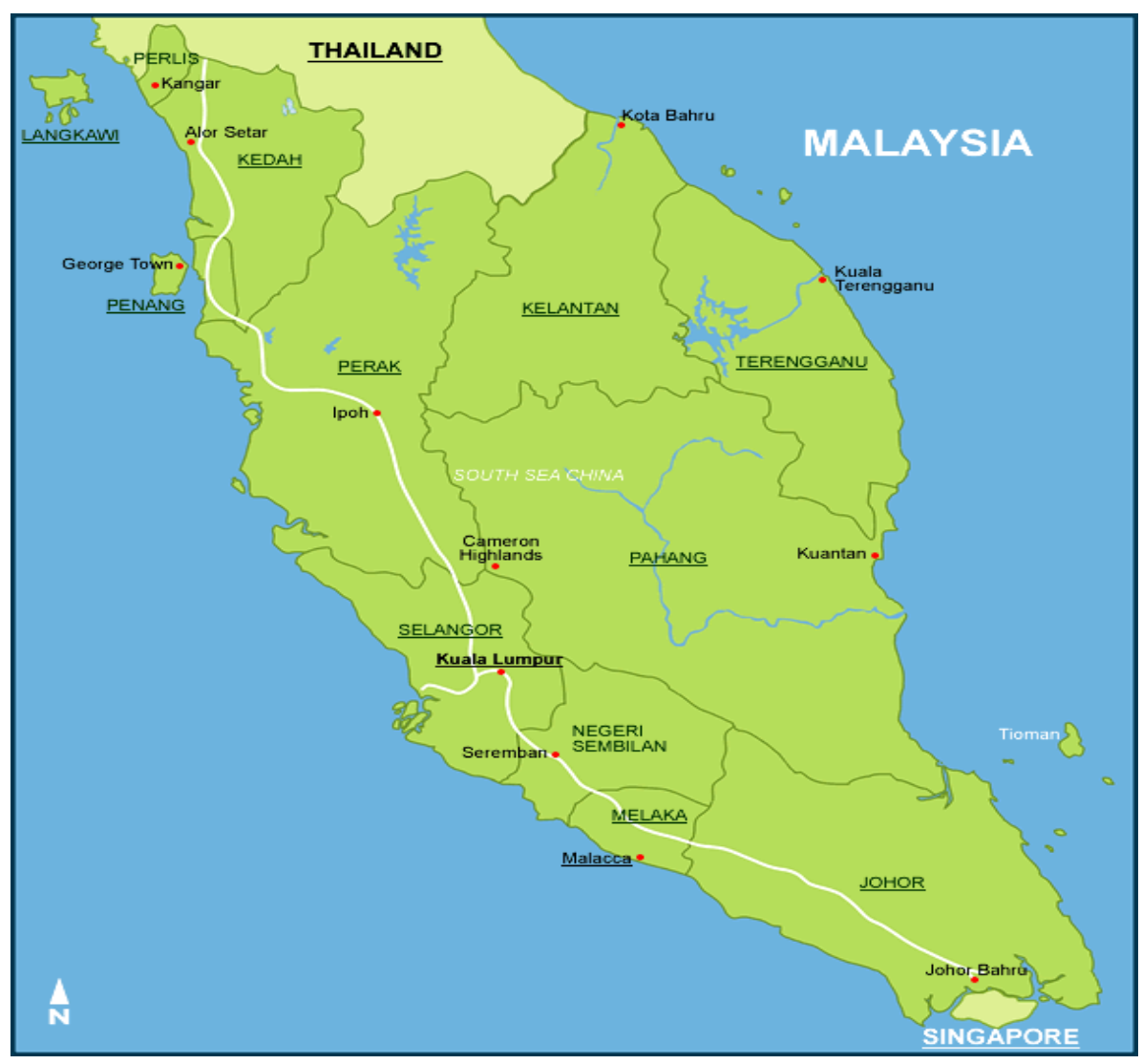

Figure 2. The location of the National Space Centre, Banting, Selangor, Peninsular Malaysia. 


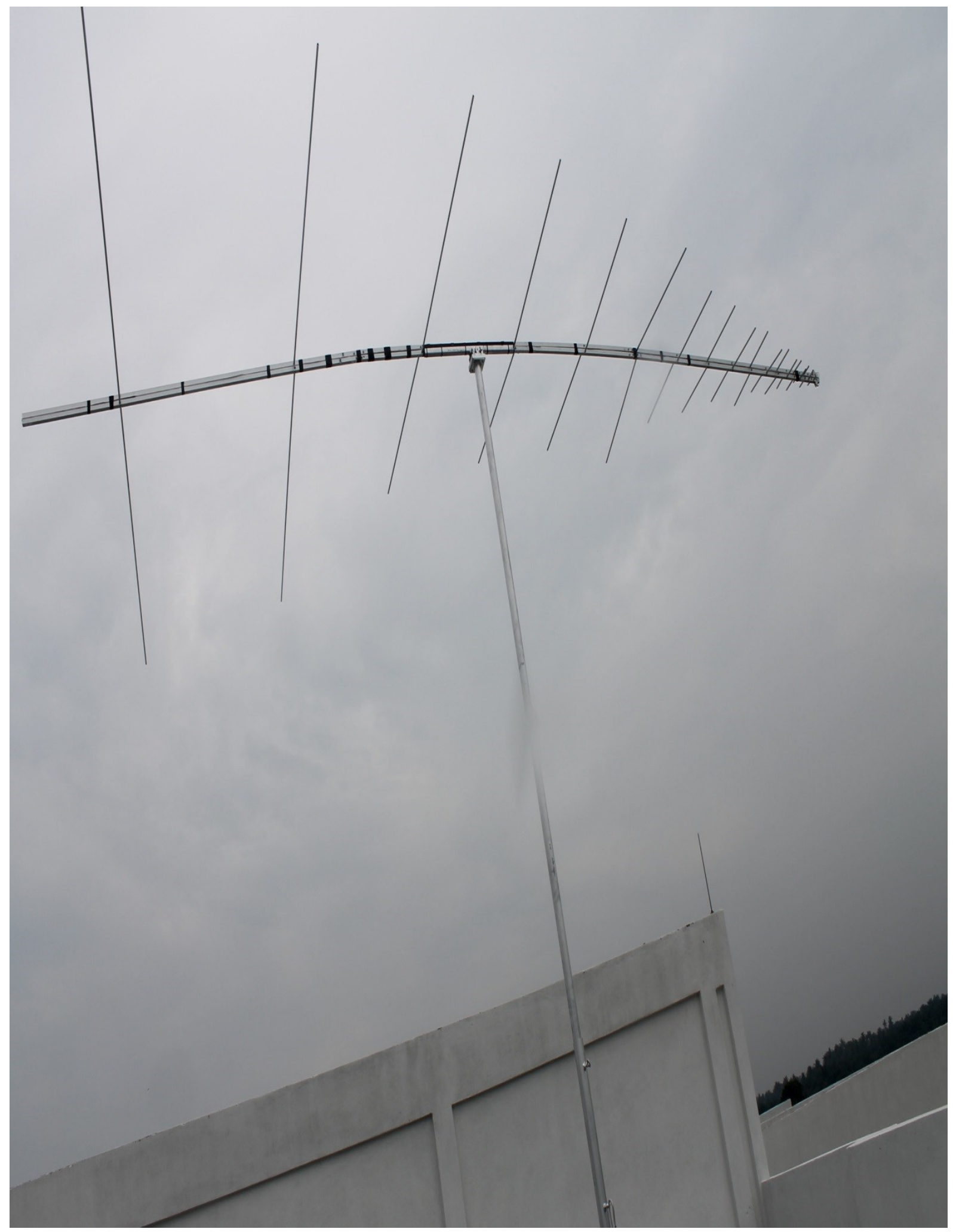

Figure 3. The installation of 5.5 meters Log Periodic Dipole Antenna at the National Space Centre Banting, Selangor Malaysia. 


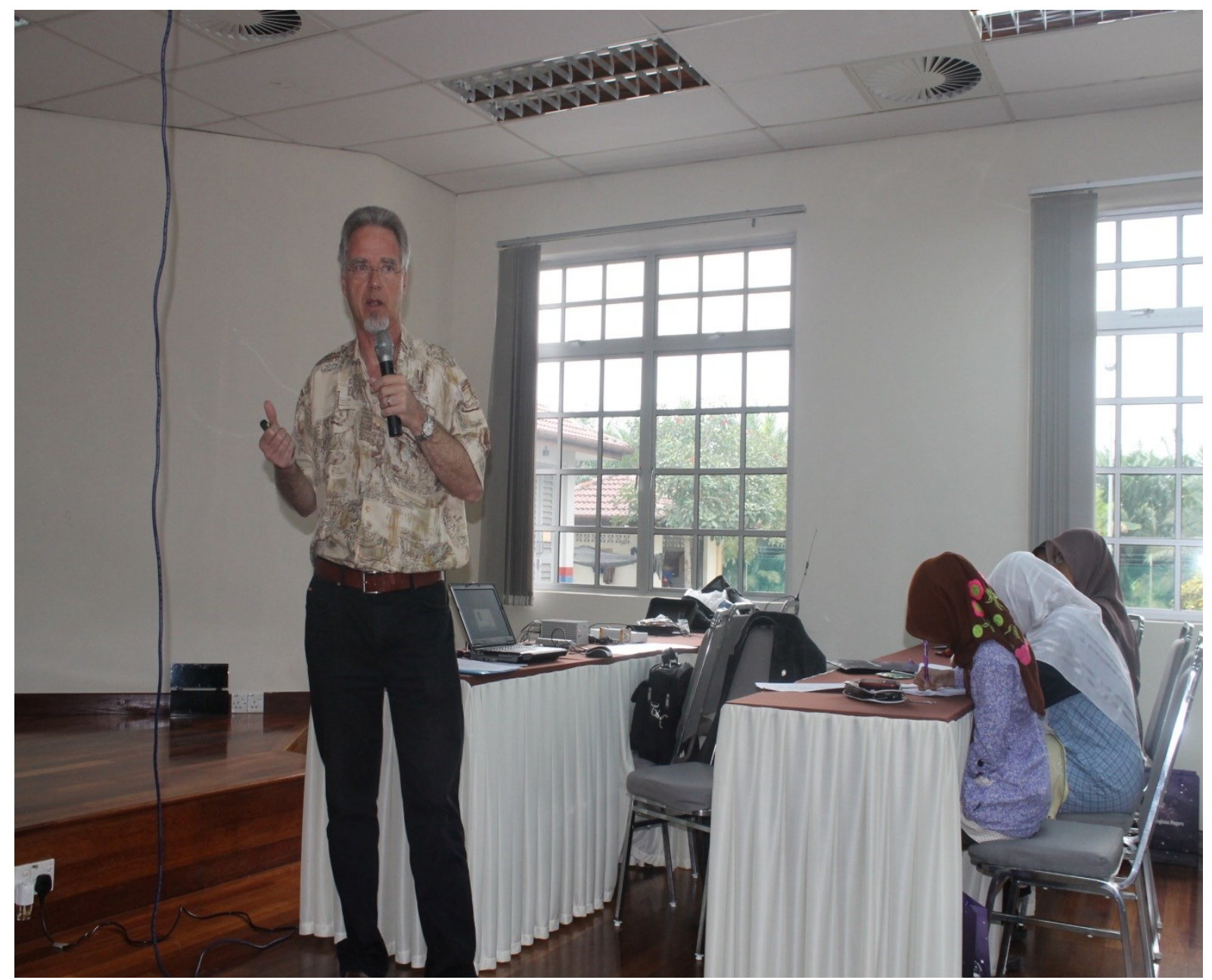

Figure 4. The workshop of analysis the CALLISTO data from $22^{\text {nd }}$ of February $-26^{\text {th }}$ of February 2012.

Figure 3 shows the installation of 5.5 meters Log Periodic Dipole Antenna (LPDA) and Figure 4 shows the participant that attend the workshop. This collaboration is the beginning of solar radio astronomy in Malaysia.

The new wavelength regime is becoming available for solar radio astronomy. Solar activities potentially affect the heliosphere in the short term (space weather) and in the long term (space climate) through numerous physical processes that exhibit similarities in various spatial domains of the heliosphere.

Understanding the nature of the motions associated with non-thermal line represents one of the major challenges of high resolution solar studies. On the basis of these works, we suggest that:

1. Future low-frequency imaging arrays are expected to greatly advance our understanding of the bursts and their relation to CMEs.

2. Observations for 24 hours on solar radio burst monitoring by e-CALLISTO, which will make it possible in a short period of time to make a new study focusing on modelling the solar radio data. 


\section{CONCLUSION}

Overall, this article presents an overview of optical and radio astronomy in Malaysia. With the present level of the international collaboration, it is believed that the potential involvement of local and international scientist in solar astrophysics will increase.It is hoped that, these observations can bring upon large scale impact by illuminating the nature of the evolution of the solar burst and the role of that evolution in generating solar activity.

\section{ACKNOWLEDGEMENT}

This work was partially supported by the PPP UM PV071/2011B grants. Special thanks to C. Monstein from ETH Zurich, Switzerland who set up and gives us training on analyzing the data. Also to National Space Agency and National Space Centre for giving us a site to set up this project and support this project. Solar burst monitoring is a project of cooperation between the Institute of Astronomy, ETH Zurich, and FHNW Windisch, Switzerland, MARA University of Technology and University of Malaya. This paper also used NOAA Space Weather Prediction Centre (SWPC) for the sunspot, radio flux and solar flare data for comparison purpose. The research has made use of the National Space Centre Facility and a part of an initiative of the International Space Weather Initiative (ISWI) program

\section{BIOGRAPHY}

Dr Zety Sharizat Hamidi is currently a lecturer and focused in Solar Astrophysics research specifically in radio astrophysics at the School of Physics and Material Sciences, Faculty of Sciences, MARA University of Technology, 40450, Shah Alam, Selangor, Malaysia. Involve a project under the International Space Weather Initiative (ISWI) and also a lecturer in School of Physics and Material Science, at MARA University of Technology, Shah Alam Selangor.

C.Monstein is a senior Engineer at Institute of Astronomy, Wolfgang-Pauli-Strasse 27, Building HIT, Floor J, $\mathrm{CH}-8093$ Zurich, Switzerland and one of the researchers who initiated the CALLISTO system around the world.

Dr Nur Nafhatun Md Shariff is a senior lecturer in Academy of Contemporary Islamic Studies (ACIS), MARA University of Technology, 40450, Shah Alam, Selangor, MalaysiaHer current research is more on sustainability; environmental aspect. She is looking forward for cross-field research, i.e. solar astrophysics, light pollution measurement (mapping) and religious studies. (Times New Roman 10)

\section{References}

[1] S.M. White, Asian Journal of Physics 16 (2007) 189-207.

[2] J.S. Hey, S.J. Parsons, J.W. Phillips, Monthly Notices of the Royal Astronomical Society 108 (1948) 354-371.

[3] R. Tousey, The solar corona, in: M.J. Rycroft, S.K. Runcorn (Eds.), Space Research XIII, Proceedings, Akademie-Verlag, Berlin, Madrid, Spain, 10 - 24 May, 1972, pp. 713730.

[4] N. Gopalswamy, Geophys. Res. Lett 27 (2000).

[5] R.A. Howard, Sheeley Jr, N.R., Michels, D.J., Koomen, M.J., J. Geophys. Res. 90 (1985) 8173-8191. 
[6] M. Pick, Solar and Space Weather Radiophysics., in: D.E. Gary, C.U. Keller (Eds.), Dordrecht, 2004, pp. 17-45.

[7] R.M.E.a.H. Illing, A.J., J. Geophys. Res. 90 (1985) 275-282.

[8] Z. Hamidi, Z. Ibrahim, Z. Abidin, M. Maulud, N. Radzin, N. Hamzan, N. Anim, N. Shariff, Designing and Constructing Log Periodic Dipole Antenna to Monitor Solar Radio Burst: e-Callisto Space Weather Project, (2011).

[9] Z.S. Hamidi, C. Monstein, Z.Z. Abidin, Z.A. Ibrahim, N.N.M. Shariff, International Journal of Engineering Research and Development 3 (2012) 36-39.

[10] Z.S.Hamidi, Z. Abidin, Z. Ibrahim, C. Monstein, N. Shariff, International Journal of Fundamental Physical Sciences 2 (2012) 32-34.

[11] Z.S.Hamidi, N.M.Anim, N. N.S.Hakimi, N.Hamzan, A.Mokhtar, N.Syukri, S.Rohizat, I.Sukma, Z.A. Ibrahim, Z.Z.Abidin, N.N.M.Shariff, C.Monstein, International Journal of Fundamental Physical Sciences 2 (2012) 4.

[12] Z.S.Hamidi, Z. Abidin, Z. Ibrahim, N. Shariff, C. Monstein, Malaysian Journal of Science and Technology Studies 9 (2013) 15-22.

[13] Z.S.Hamidi, Z. Abidin, Z. Ibrahim, N. Shariff, Indication of radio frequency interference (RFI) sources for solar burst monitoring in Malaysia, ICPAP 2011, AIP Publisher, Indonesia, 2012, pp. 6.

[14] Z.S. Hamidi, N.N.M.Shariff, C.Monstein, International Letters of Natural Sciences 5 (2014) 10-17.

[15] Z.S. Hamidi, Z.Z. Abidin, Z.A. Ibrahim, N.N.M. Shariff, U.F.S.U. Ibrahim, R. Umar, Preliminary analysis of investigation Radio Frequency Interference (RFI) profile analysis at Universiti Teknologi MARA, IEEE, 2011, pp. 311-313.

[16] Z. Hamidi, N. Shariff, International Letters of Chemistry, Physics and Astronomy 5 (2014) 43-49.

[17] N. Hashim, Z. Abidin, U. Ibrahim, R. Umar, M. Hassan, Z. Rosli, Z. Hamidi, Z. Ibrahim, Radio Astronomy in Malaysia: Current Status and Outreach Activities, Astronomical Society of the Pacific Conference Series, 2011, pp. 355.

[18] Z.S.Hamidi, S. Chumiran, A. Mohamad, N. Shariff, Z. Ibrahim, N. Radzin, N. Hamzan, N. Anim, A. Alias, American Journal of Modern Physics 2 (2013) 4.

[19] Z.S. Hamidi, N. Shariff, Z. Abidin, Z. Ibrahim, C. Monstein, Middle-East Journal of Scientific Research 12 (2012) 6.

[20] Z. Hamidi, N. Shariff, C. Monstein, Z. Ibrahim, International Letters of Chemistry, Physics and Astronomy 7 (2014) 37-44.

[21] A.O. Benz, C. Monstein, H. Meyers, CALLISTO, A New Concept for Solar Radio Spectrometer, Kluwer Academic Publishers, The Netherland, 2004. 